\title{
PROPOFOL - REMIFENTANIL VERSUS MIDAZOLAM - FENTANYL IN CORONARY ARTERY BYPASS GRAFT SURGERY AND INTENSIVE CARE UNIT
}

\author{
TWANA TAHER QADER, MBChB, FICM.S* \\ OTHMAN ISMAT ABDULMAJEED, MBChB, FICMS** \\ ABDULQADIR M. ZANGANA, CABS, FI.MS***
}

\section{Submitted 3/1/2017; accepted 28/2/2017}

\begin{abstract}
Background: In this study, we aim to identify the efficiency of propofol-remifentanil anesthesia in reducing the postoperative intensive-care unit stay in patients undergoing cardiac surgery in our center, without compromising the hemodynamic stability.

Subject and Methods: Two hundred patients undergoing first time elective coronary artery bypass graft surgery were recruited in this single-centered, single-blinded, prospective and controlled study. Study patients were randomized into two treatment groups: group 1 (P-R; Propofol-Remifentanil) (n=100 patients) and group 2 (M-F; Midazolam-Fentanyl) (n=100 Patients). Clinical measurement of Mean arterial blood pressure and heart rate for each patient were recorded before (T1) and after (T2) induction of anesthesia; after sternotomy (T3) and before cardiopulmonary bypass (CPB) (T4). Time from cessation of anesthesia to tracheal extubation was also recorded (T5).

Results: Comparing the hemodynamic parameters between the two groups at T1, T2, T3 and $\mathrm{T} 4$ set points revealed statistically significant difference $(\mathrm{P}<0.5)$ in hemodynamic variables in all parameters measured apart from HR at T3. The mean recorded times from cessation of anesthesia to tracheal extubation (T5) were 99.32 minutes and 183.33 minutes in group 1 and 2 , respectively. A statistically significant difference was noted between $\mathrm{T} 5$ in both groups (P value $=0.003$ ).

Conclusions: Our study has shown that Propofol-Remifentanil anesthesia helps to reduce the time interval between cessation of anesthesia and extubation and, by doing so, it can potentially reduce the postoperative ICU stay, without compromising hemodynamic stability.
\end{abstract}

Duhok Med J 2017; 11 (1): 39-47.

Keywords: Cardiac anesthesia, Propofol, Remifentanil, Midazolam, Fentanyl, elective CABG surgery, hemodynamics, depth of anesthesia, ICU.

$\begin{array}{ll}\text { Cardiovascular stability is an } & \text { provided by using high doses of opioids to } \\ \text { essential prerequisite for } & \text { suppress hormonal and metabolic stress } \\ \text { cardiac anesthesia, where } & \text { responses to surgical stimuli. This regimen } \\ \text { myocardial protection is vital in } & \text { resulted in reduced morbidity and } \\ \text { patients who already have } & \text { mortality after cardiac surgery }{ }^{1} \text {. However } \\ \text { compromised cardiovascular } & \text { high doses or prolonged administration of } \\ \text { function. Traditionally, profound } & \text { conventional opioids can result in their } \\ \text { intraoperative analgesia has been } & \text { accumulation, leading to postoperative }\end{array}$

* Anesthesia Specialist, Erbil Cardiac Center, Erbil, Kurdistan Region, Iraq

**Lecturer, College of Medicine, Hawler Medical University, Erbil, Kurdistan Region, Iraq

***Professor, Department of Surgery, College of Medicine, Hawler Medical University, Erbil, Kurdistan Region, Iraq.

Correspondence author to: Othman I Abdulmajeed, othamn.abdulamjeed@med.hmu.edu.iq., 
respiratory depression and prolonged Intensive Care Unit (ICU) stay ${ }^{2}$.

Due to economic considerations, many centers adopts cardiac anesthesia regimens using intermittent low- to medium-dose opioids to reduce time to extubation and postoperative ICU and hospital stay. Such regimens have been shown to allow reduction in extubation time and hospital stay with no significant postoperative sequelae in low-risk cardiac patients ${ }^{3}$.

Goals of anesthesia for coronary artery bypass graft (CABG) surgery include hypnosis, hemodynamic stability, neurohumoral stress ablation ${ }^{4}$ and may include early tracheal extubation ${ }^{5}$. Fasttrack cardiac surgery is partly dependent on smaller-dose opioid regimens and although these may be associated with increased hemodynamic responses during surgery, there is no apparent increased risk of complications ${ }^{5}$.

Propofol in combination with opioids is widely used in cardiac surgery providing the benefit of early extubation ${ }^{6,7}$. This may help to reduce costs by reducing the postoperative ICU stay ${ }^{8}$.

In this study, we aim to identify the efficiency of propofol-remifentanil anesthesia in reducing the postoperative ICU stay in patients undergoing cardiac surgery in our centre, without compromising the hemodynamic stability.

\section{PATIENTS AND METHODS}

Two hundred patients undergoing first time elective CABG surgery were recruited in this single-centered, singleblinded, prospective and controlled study. Inclusion criteria for the study were patients with good or only slightly reduced left ventricular function (left ventricular ejection fraction (LVEF) of more than $40 \%$ ) and younger than 82 years old. Exclusion criteria included weight of more than 100 kilograms (kg), confirmed diagnosis of uncontrolled hyper- and / or hypotension, congestive cardiac failure, atrioventricular or left bundle branch block detected on their preoperative electrocardiogram (ECG), valvular heart disease and patients with severe hepatic or renal insufficiency, pacemaker in situ, previous coronary artery bypass grafting (CABG) surgery, previous alcohol misuse and / or hypersensitivity to opioids or Propofol-lipid emulsion.

Study patients were randomized into two treatment groups: group 1 (P-R; PropofolRemifentanil) (n=100 patients) and group 2 (M-F; Midazolam-Fentanyl) $\quad(n=100$ Patients). Out of 200 patients, 8 patients were excluded (4 patients developed bleeding less than an hour after admission to ICU and 4 patients developed intraoperative congestive heart failure). Patients' regular prescribed medications were continued until the time of operation. In both groups, the dose of the anesthetic medications was adapted to ensure optimal anesthetic and surgical conditions, whilst maintaining hemodynamic stability. The dose of Propofol-Remifentanil or Midazolam-Fentanyl was increased when heart rate (HR) and / or systolic blood pressure increased by $20 \%$ from baseline values and when sweating or lacrimation was observed.

In group 1, induction of anesthesia was achieved using a continuous infusion of Remifentanil (1 microgram / kg / minute) and Propofol (1-1.5 milligram / kg / minute) with Isoflurane (1-1.5 MAC). Five minutes later, Atracurium (0.4 milligram / 
$\mathrm{kg}$ ) was given as a bolus intravenous injection followed by endotracheal intubation. Mechanical ventilation was secured using with a tidal volume of 7 milliliters / $\mathrm{kg}$, respiratory rate of 10 cycles / minute and an Inspiration: Expiration (I:E) ratio of 1:2 (GE Datex-Ohmeda anesthesia machine).

Maintenance of anesthesia was achieved by continuous infusion of a reduced dose of Remifentanil (0.2-0.5 micrograms / kg / minute) and Propofol which was run by increments of 50 micrograms / kg / minute (infusion between 100 and 250 micrograms / kg / minute).

In group 2, patients were induced by bolus intravenous dose of Midazolam (0.07 milligrams / kg) and Fentanyl (5-10 micrograms $/ \mathrm{kg}$ ). Tracheal intubation was performed in the similar fashion to group 1. After intubation, intermittent bolus doses of Fentanyl (5-10 micrograms / kg) were administered. Further doses of Midazolam were given as an intravenous bolus (0.03-0.07 milligrams / $\mathrm{kg}$ ), as indicated by the attending anesthesiologist. Mechanical ventilation and muscle relaxation were performed as in group 1 .

Clinical measurement of arterial blood pressure and heart rate for each patient were recorded before (T1) and after (T2) induction of anesthesia; after sternotomy (T3) and before cardiopulmonary bypass (CPB) (T4), using GE Healthcare Carescape B650 compact patient monitor. Time from cessation of anesthesia to tracheal extubation was also recorded (T5). Patient monitoring consisted of five-lead ECG. Correct ECG ST Segment monitoring was confirmed (with definition of isoelectric line and $\mathrm{J}$ point), pulse oximetry, capnography and invasive arterial pressure. Intravascular catheters were inserted after induction of anesthesia. Continuous three-lead (II, aVL, V5) automated ST segment analysis was used to detect intraoperative myocardial ischemia.

Following surgery, analgesia consisted of Morphine intravenous infusion of 1-2 milligrams / hour. Patients' remained intubated and mechanically ventilated whilst being transferred to ICU. As soon as patients' responded to verbal stimuli, were normothermic and hemodynamicallystable and their estimated blood loss were within the acceptable level (less than 100 milliliters / hour), patients were weaned off mechanical ventilation. Tracheal extubation was achieved when the patient was awake and cooperative, with a respiratory rate of 10-20 breaths / min and had satisfactory arterial blood gas analyses.

The data were analyzed using statistical package of social science SPSS Version 18. Statistical $\mathrm{T}$ test was used to analyze the difference in the variables of both group. A P value of $\leq 0.05$ was considered statistically significant.

\section{RESULTS}

One hundred ninety two patients aged 4082 years (145 males and 47 females; with a Male: Female ratio of $3: 1)$ completed our study (Table 1). Out of 192, 66 (34.4\%) patients had hypertension well controlled on regular medication(s) and 41 (21.3\%) patients were known diabetic. 


\begin{tabular}{ccc}
\hline \multicolumn{3}{c}{ PROPOFOL - REMIFENTANIL V } \\
\hline & Table 1: & Gender frequency \\
\hline Gender & Frequency & Percentage (\%) \\
\hline Female & 47 & 24.4 \\
Male & 145 & 75.5 \\
Total & 192 & 100 \\
\hline
\end{tabular}

MABP showed slight drop after induction of anesthesia followed by mild rise during sternotomy in both groups as shown in Figure 1. Changes in mean HR during the study are illustrated in Figure 2. Before going on CPB, a further drop in MABP was noticed without a significant change in HR (Figures 1 and 2).

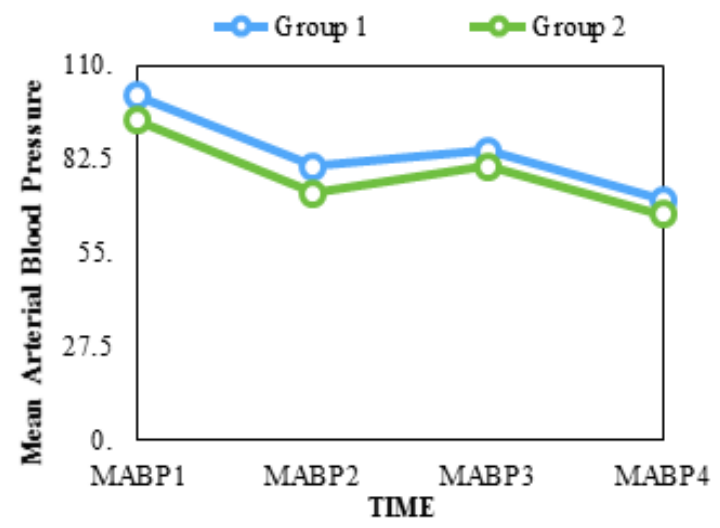

Figure 1. Changes in mean arterial blood pressure measurement according to time sets in group 1 (blue) and 2 (Green).

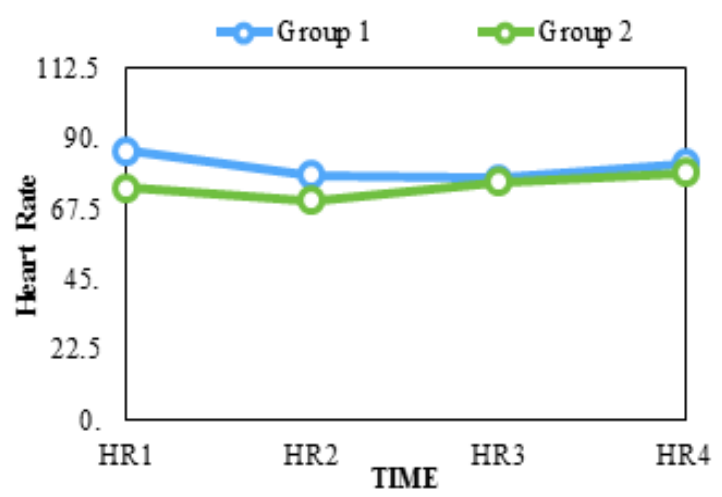

Figure 2. Changes in heart rate measurement according to time sets in group 1 (Blue) and 2 (Green).

Table 2: The difference in mean arterial blood pressure measurement (MABP) between the two groups.

\begin{tabular}{|c|c|c|c|c|c|}
\hline \multirow{2}{*}{\multicolumn{2}{|c|}{$\begin{array}{l}\text { Regimen of } \\
\text { anesthesia }\end{array}$}} & \multicolumn{4}{|c|}{ МАВР } \\
\hline & & $\mathbf{T 1}$ & $\mathbf{T} 2$ & T3 & T4 \\
\hline \multirow{2}{*}{$\begin{array}{c}\text { R-P } \\
\text { group } \\
(n=93)\end{array}$} & Mean & 101.2 & 80.5 & 85 & 70.5 \\
\hline & $\begin{array}{c}\text { Std. } \\
\text { Deviation }\end{array}$ & 16.5 & 11.5 & 13.5 & 11.4 \\
\hline \multirow{2}{*}{$\begin{array}{l}\text { M-F } \\
\text { group } \\
(n=99)\end{array}$} & Mean & 94 & 72.5 & 80.3 & 66.1 \\
\hline & $\begin{array}{c}\text { Std. } \\
\text { Deviation }\end{array}$ & 20.2 & 10.9 & 14.7 & 13.9 \\
\hline \multicolumn{2}{|c|}{ P-value } & 0.15 & 0.008 & 0.21 & 0.2 \\
\hline
\end{tabular}

Table 3: The difference in heart rate measurement (HR) between the two groups.

\begin{tabular}{|c|c|c|c|c|c|}
\hline \multirow{2}{*}{\multicolumn{2}{|c|}{$\begin{array}{l}\text { Regimen of } \\
\text { anesthesia }\end{array}$}} & \multicolumn{4}{|c|}{ HR } \\
\hline & & T1 & $\mathbf{T} 2$ & T3 & T4 \\
\hline \multirow{2}{*}{$\begin{array}{c}\text { R-P } \\
\text { group } \\
(\mathbf{n}=93)\end{array}$} & Mean & 86.3 & 78.5 & 77.44 & 82.2 \\
\hline & $\begin{array}{c}\text { Std. } \\
\text { Deviation }\end{array}$ & 19.5 & 15.1 & 25.1 & 17 \\
\hline \multirow{2}{*}{$\begin{array}{l}\text { M-F } \\
\text { group } \\
(n=99)\end{array}$} & Mean & 74.3 & 70.3 & 76.1 & 79.1 \\
\hline & $\begin{array}{c}\text { Std. } \\
\text { Deviation }\end{array}$ & 13.7 & 13.5 & 12.6 & 14.8 \\
\hline \multicolumn{2}{|c|}{ P-value } & 0.007 & 0.33 & 0.79 & 0.44 \\
\hline
\end{tabular}

The mean recorded times from cessation of anesthesia to tracheal extubation (T5) were 99.32 minutes and 183.33 minutes in

Comparing MABP and HR between the two groups at T1, T2, T3 and T4 set points revealed statistically significant difference $(\mathrm{P}<0.5)$ in hemodynamic variables in all parameters measured apart from $\mathrm{HR}$ at $\mathrm{T} 3$ detailed in (Table 2 and 3). 
group 1 and 2, respectively. A statistically significant difference was noted between $\mathrm{T} 5$ in both groups $(\mathrm{P}$ value $=0.003$; Figure3).

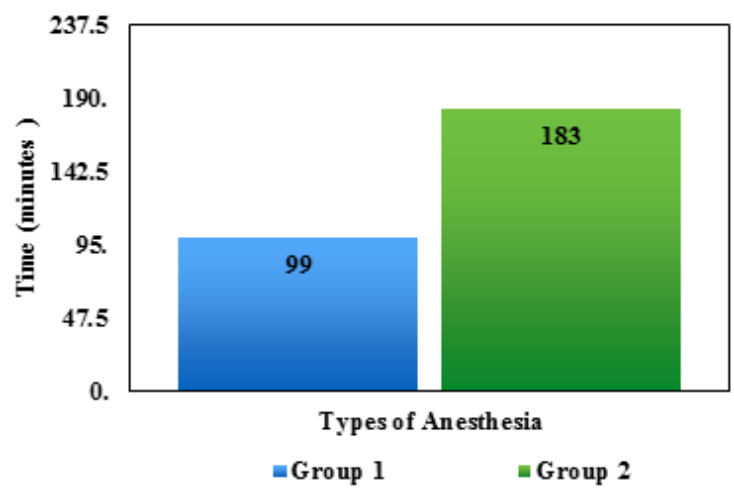

Figure (3). The difference in the meantime from cessation of anesthesia to tracheal extubation between the two groups, in minutes.

\section{DISCUSSION}

In this prospective single-blinded, randomized and controlled study, we analyzed the hemodynamic effects of Remifentanil - Propofol compared with Fentanyl - Midazolam regimens in patients undergoing CABG surgery aiming to identify the efficiency of propofolremifentanil anesthesia in achieving early tracheal extubation and reducing the postoperative ICU stay without compromising the hemodynamic stability throughout surgery.

Given the possible relationship between the neurohumoral stress response and postoperative myocardial ischemia, largedose opioid use have been the preferred technique in many centers 9 . Our study suggests that Remifentanil can provide this effect without prolonging recovery times.

Comparing the hemodynamic results from group 1 in our study to those from another study performed by Lehmann and colleagues in Germany in 2000, we identified a higher MABP after induction of anesthesia and during sternotomy in our patients. The former study pre-medicated their patients orally with 1-2mg Flunitrazepam and used Propofol as targetcontrolled infusion with calculated plasma concentration of 3 micrograms / milliliters. Also, the change in HR in our P-R group after induction of anesthesia were nearly similar to those from Lehmann et al study. However, after sternotomy the changes in HR in our study P-R group were with higher standard deviation compared to Lehmann et al study ${ }^{8}$.

This can be explained by the fact that a significant number of our patients had an increase in HR after sternotomy, shifting the calculated standard deviation. Having said that, the overall mean HR in our study P-R group was more stable than those related to M-F group, showing the superiority of propofol-remifentanil group in maintaining hemodynamic stability during CABG.

It has been shown that adjustment of the dose of Remifentanil helps to control hemodynamics by reducing its dose when MABP is decreased or increasing the dose before potential major surgical stress events without significantly prolonging recovery time ${ }^{10}$. Also, Remifentanil, compared to Fentanyl, has a more pronounced sympathoadrenergic stimulatory effect in the early postoperative period $^{11}$. On the other hand, Propofol in combination with an opioid is already in use in cardiac surgery ${ }^{12}$.

Early extubation is shown to be the main advantage of Propofol anesthesia in cardiac surgery potentially leading to cost reduction by reducing the length of ICU stay ${ }^{11,12}$. Consistent results are obtained from our study as patients in group 1 were 
generally able to be extubated earlier than those in Group 2.

Our study shows that both PropofolRemifentanil and Midazolam-Fentanyl regimens in patients undergoing $\mathrm{CABG}$ surgery were safe and showed stable hemodynamics.

More importantly, we have shown that Propofol-Remifenatnil anesthesia helps to reduce the time interval between cessation of anesthesia and extubation and, by doing so, it can potentially reduce the postoperative ICU stay, without compromising hemodynamic stability.

\section{REFERENCES}

1. Tanaka K, Kersten JR, Riess ML. Opioid-induced Cardioprotection. Current pharmaceutical design. 2014;20(36):5696-5705.

2. Muller L, Chanques G, Bourgaux C, Louart G, Jaber S, Fabbro-Peray P, Ripart J, de La Coussaye JE, Lefrant JY.Impact of the use of propofol remifentanil goal-directed sedation adapted by nurses on the time to extubation in mechanically ventilated ICU patients: the experience of a French ICU.Ann Fr Anesth Reanim. 2008;27(6):481.e1-8. doi: 10.1016/j. annfar.2008.04.022.

3. Konagai N, Yano H, Maeda M, Misaka M, Matsumaru T, Kudo T, Ishimaru S. Evaluation for factors associated to early tracheal extubation after coronary artery bypass grafting. Kyobu Geka. 2001; 54(7):560-3.

4. Volders PG.Novel insights into the role of the sympathetic nervous system in cardiac arrhythmogenesis. Heart
Rhythm. 2010;7(12):1900-6. doi: 10.1016/j.hrthm.2010.06.003. Review

5. Wanat M, Fitousis K, Boston F, Masud F. Comparison of Dexmedetomidine versus Propofol for Sedation in Mechanically Ventilated Patients after Cardiovascular Surgery. Methodist DeBakey Cardiovascular Journal. 2014;10(2):111-117.

6. Probst S, Cech C, Haentschel D, Scholz M, Ender J. A specialized postanaesthetic care unit improves fasttrack management in cardiac surgery: a prospective randomized trial. Critical Care. 2014;18(4):468. doi:10.1186/s13054-014-0468-2.

7. Muellejans B, Matthey T, Scholpp J, Schill M. Sedation in the intensive care unit with remifentanil/propofol versus midazolam/fentanyl: a randomised, open-label, pharmacoeconomic trial. Critical Care. 2006;10(3):R91. doi:10.1186/cc4939.

8. Lehmann A, Zeitler C, Thaler E, Isgro F, Boldt J. Comparison of Two Different Anesthesia Regimens in Patients Undergoing Aortocoronary Bypass Grafting Surgery: SufentanilMidazolam Versus RemifentanilPropofol. J Cardiothorac Vasc Anesth. 2000;416-420

9. Iannuzzi E, Iannuzi M, Cirillo V, Viola G, Parisi R, Chiefari M. Small doses of remifentanil and alfentanil in continuous total intravenous anesthesia in major abdominal surgery. Minerva Anestesiol. 2003;69(3): 127-33, 133-6. English, Italian.

10. Winterhalter $\mathrm{M}$, Brandl $\mathrm{K}$, RaheMeyer N, Osthaus A, Hecker H, Hagl C, Adams HA, Piepenbrock S. Endocrine stress response and 
inflammatory activation during $\mathrm{CABG}$ surgery. Eur J Anaesthesiol. 2008;25(4): 326-35.

11. Rauf K, Vohra A, Fernandez-Jimenez P, O'Keeffe N, Forrest M. Remifentanil infusion in association with fentanylpropofol anaesthesia in patients undergoing cardiac surgery: effects on morphine requirement and postoperative analgesia. $\mathrm{Br} \mathrm{J}$ Anaesth. 2005;95(5):611-5.
12. Newman M, Reves JG. Pro Midazolam is the sedative of choice to supplement narcotic anesthesia. $\mathbf{J}$ Cardiothorac Vasc Anesth. 1993;7:615619. 


\section{ثوختة}

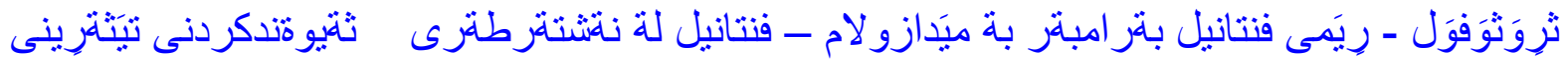

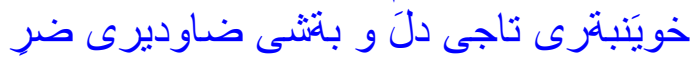

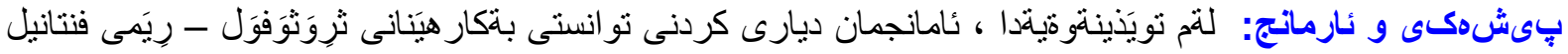

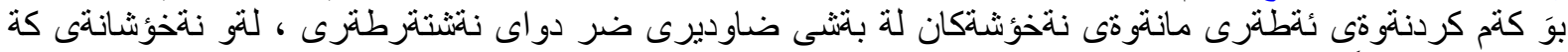

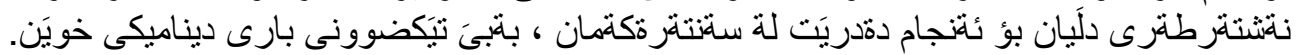

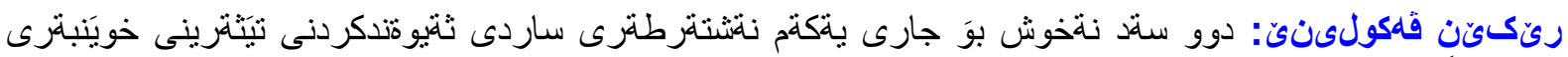

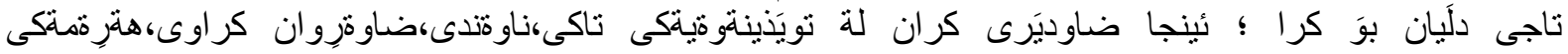

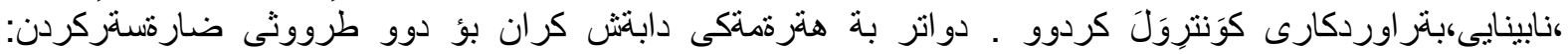

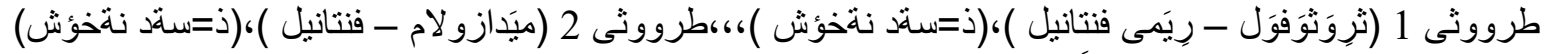

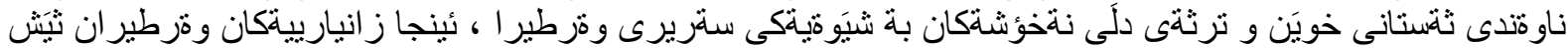

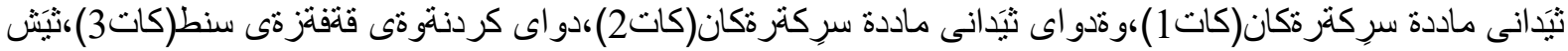

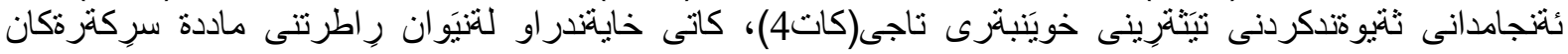

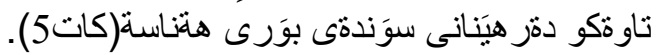

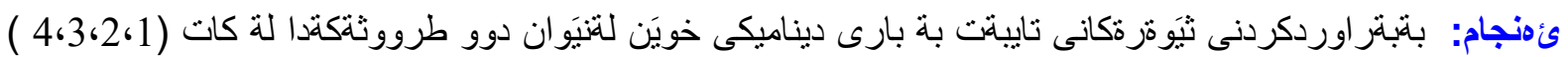

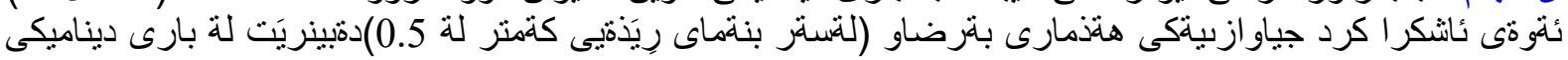

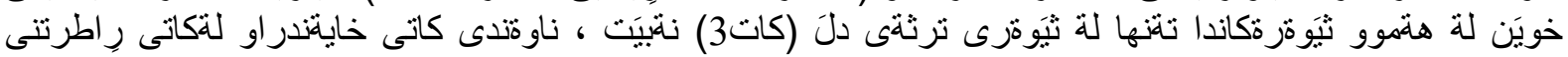

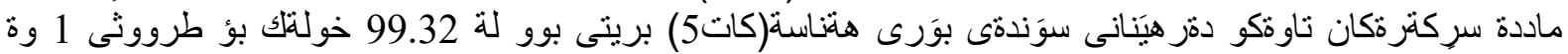

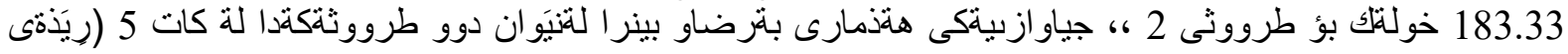

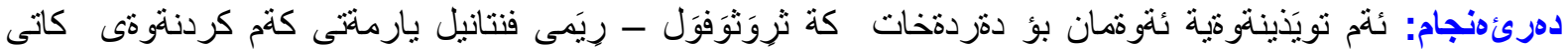

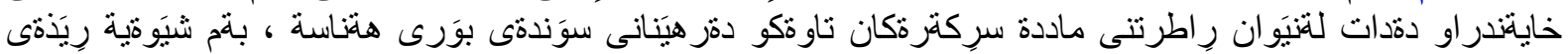

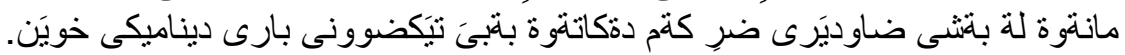




\section{الخلاصة}

برويوفول - ريميفيتانيل مقارنة ب ميدازولام - فينتانيل في عمليات زرع الثرايين التاجية والعناية المركزة

خلفية وأهداف البحث: في هذه الدراسة، هدفنا هو ايجاد فعالية دواء البرويوفول- ريميفينتانيل لغرض تقليص وقئ وقت بقاء

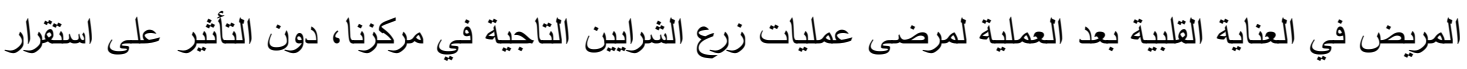

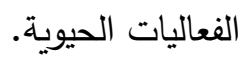

طرائق البحث: مائتين مريض تجرى لهم عملية زرع شرايين تاجية لاول مرة. مئة من المرضى اعطوا تخدير البروبوفول

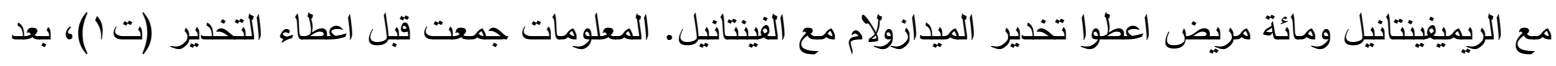

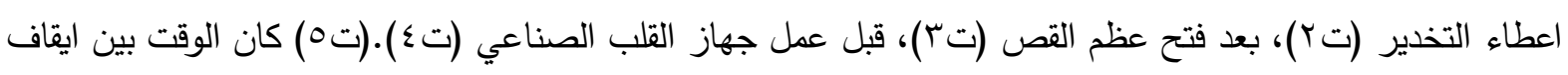

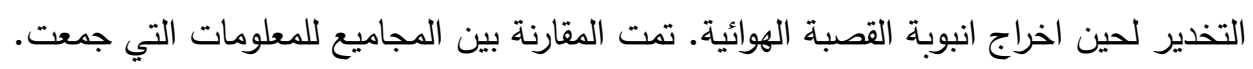

النتائج: كان هناك فرق واضح في قراءات الدورة الدموية في ت (، ت ؟، ت ب و ت ؛ بين الدجموعتين.

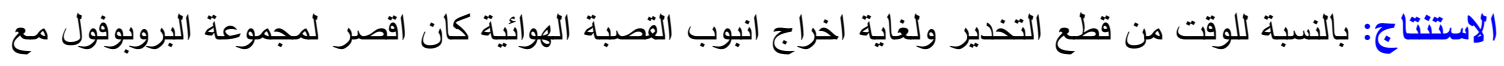

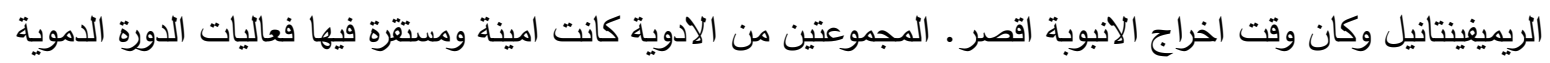
اثناء عملية زرع الثرايين التاجية. 